\title{
Moulding of Aesthetics in Vocal Music Teaching
}

\author{
Lijuan Li \\ Music Department, XingTai University, Xingtai, 054000, China
}

\begin{abstract}
As the most fundamental and the most principal part in music education, vocal music teaching receives the attention from scholars. There are more and more explorations for and reflections on aesthetics. As a kind of art form, vocal music teaching should be reviewed under the framework of music and aesthetics. On this basis, the author discussed in this paper the moulding of aesthetics in vocal music teaching.
\end{abstract}

Key words: vocal music teaching, aesthetics, mould

With a long history in China, vocal music is a kind of musical form with instruments and human voice as carriers. Many things seemingly irrelevant have lots of relations inside. In the process of literary and artistic activities developed by human beings, beauty is an object in objective existence. Each person has psychological reaction to stimulate beauty. This psychological reaction usually needs to be formed through imagination, perception, emotion and thought. However, the aesthetic consciousness is just served as the basis for the formation of musical aesthetics. All pursuits for and realization forms of beauty in the world are served as the essence of literature and art as well as one of similarities of aesthetic characteristics.

\section{Significance of Moulding of Aesthetic Consciousness}

1. For improvement to the learning efficiency of vocal music, the aesthetic consciousness should be cultivated.

For a student majoring vocal music, the time for learning is extremely limited. Due to the particularity of vocal music in learning and life, students often were influenced by many factors. Therefore, the students should have an objective understanding of their advantages and disadvantages. However, the students should not look down upon themselves at random. Instead, they should give play to their advantages and avoid their disadvantages as much as possible. Only in this way, they can be improved in a short period. It will result in a waste of time and energy, if there are no aesthetic criteria for correct singing styles and singing methods in the development of teaching activities, or the students failed to understand or have 
complete and correct evaluation for themselves or a complete understanding of vocal music art. With continuous development of diversified culture, pop and classical cultural concepts are mutually influenced and penetrated day by day. At the same time, great changes also occurred in people's aesthetic criteria and aesthetic tendency. For improvement to their aesthetic judgment, therefore, the students must be cultivated with the moulding of aesthetic consciousness. In the process of learning, the students should learn about relevant knowledge effectively and never waste unnecessary learning energy and time, so as to improve teaching efficiency and learning efficiency.

Only continuous improvement to students' vocal music aesthetic consciousness can make them to positively utilize their ideas and criteria to teach and take advantage of their singing, reflect the essence of music art and have the ability to evaluate and realize the sinning level, so as to improve their artistic level.

\section{Aesthetic consciousness is served as an important link between aesthetic moulding and vocal music teaching.}

Actually, all literature and arts in the world are continuously pursuing for and realizing beauty. It is the common pursuit of each aesthetic characteristic. In internal relations between art and aesthetics, vocal music art is a very obvious part as well as a law which can fully reflect aesthetic laws. In the vocal music art, "beauty" is the core of art. Due to diversified and complicated thoughts of people and coexistence with objective things, however, beauty is understood and realized from multiple aspects and inclinations. In the overall music education, therefore, the failure to organically connect vocal music teaching with aesthetic education is often caused by insufficient importance attached to the internal essence of vocal music art.

Then, how the integration between the aesthetic essence and vocal music teaching should be understood and realized? In terms of moulding of aesthetic consciousness, we should provide students with the maximum background and materials for aesthetic imagination, cultivate the students' habits to listen to vocal music works on the basis of lacking aesthetic environment, allow the students to be in activities of continuously appreciating music and discussing music, and change originally unfamiliar condition of students toward all kinds of music into appreciation and love of music by continuously expanding the scale of music appreciation and continuously listening to music and from rejection and dislike into gradual 
acceptance, love and appreciation, so as to enhance the feeling and comprehension level of music beauty.

Through the guidance to the students, we can allow them to associate with other similar musical works or make a contrast with other composers' works through a category of works, associate from the basic compression to profound \& systematic feeling and appreciation the beauty of vocal music works and allow the students to further experience and feel internal artistic conception, significance and taste of music, so as to gradually improve their ability to appreciate music. For instance, most students failed to experience in person German and Austrian culture and art atmosphere, while learning about German and Austrian art songs. To correctly reflect music characteristics and artist forms of composition, it is necessary to continuously cultivate aesthetic consciousness and take full advantage of guidance, description, making and other methods to provide relevant learning materials to students. Through learning and comprehension of these materials, the students will reflect these materials though their emotions and feelings and form good aesthetic psychology, so as to reach the fundamental objective of teaching.

\section{Approaches for Moulding of Aesthetic Consciousness in Vocal Music Teaching}

\section{Moulding of aesthetic consciousness in vocalization practice}

Good voice is the principal precondition for the beauty of human voice. Then, it is composed of systematic, scientific and professional voice training. Good voice is served as the basis for the beauty of vocal music. However, it is far from enough by only relying on inborn voice conditions. A really good sense of music beauty needs the cultivation of music. A good aesthetic consciousness of vocal music should be shaped through systematic and reasonable voice training. For instance, certain influence will be caused to the resonance chamber, if the students were engaged in inspiration during the training for three-dimensional syllable. At the same time, the position of breath was also improved much. However, it doesn't work by simply teaching the students to "breathe in and never increase the breath". At this moment, the process of suction can be regarded as a movement to smell the potpourri of a rose. Students can be guided to how to learn through aesthetic methods. In the practical teaching process, the students can understand the essential elements of suction in a short period through this method. In the process of hum training, many students would result in "block”, "squeeze” and muscle tenseness due to incorrect 
methods of opening the mouth. At this moment, the students should be made to open their throats and cavities. Usually, it would fail to reach the teaching objective. At this moment, the students should be provided with practical and effective aesthetic guidance, for instance, the feeling of being scared by a black bear or the feeling of failing to sneeze. Thus, the students can analyze methods to open their mouths in a short period and restore originally tight muscles. In the process of classroom teaching and voice training, we used to encounter the deficiency of emotion in the voice, which belongs to a kind of relatively mechanical state. If teachers failed to pay enough attention in the teaching process, it will fail to reach expected teaching effects. At this moment, teachers need to offer positive guidance to students. Voice etude is a length of wonderful melody with independent musical image and character instead of a voice etude used in voice training. Syllables representing emotions are extreme ones. Syllables representing determination or loftiness are three-degree skipping ones. Dramatic tension is represented by three-dimensional implementation with a large span. The students can be made to release themselves for relaxation through dramatic tension. Due to breath sinking and excitement, the resonance chamber is opened after breath sinking. Emotions, voice and breath are organically combined. Therefore, teachers should pay attention to the guidance to the students' aesthetics while performing voice training for students, so as effectively improve the classroom interaction, train the artistic imagination and thinking mode of students and effectively improve the aesthetic concept of vocal music teaching.

\section{Establish accurate voice concept and aesthetics}

The first step for people to percept music is to listen to the music. A kind of auditory art is called vocal music. The process of music singing and appreciation is called vocal music art activity. In the process of music learning, the most principal process is listening, which is also served as the condition for feeling and appreciation of music. In the process of music education, therefore, teachers must put the cultivation of students' auditory sense at the first place. "Listen" is the beginning of all music education activities. Therefore, students should have favorable and keen auditory sense. After the entrance, new comers began to contact each class. The habit of listening must be cultivated. Before the university, most students failed to have a complete understanding of music image and sufficient cognition of music. The aesthetic ability of vocal music can be shaped only by 
letting the students continuously listen to their voice, good musical works and other's telling. Therefore, the students must be taught about how to listen to others by teachers.

At the same time, students can appreciate the beauty of music and music language after listening. Starting with music language, the students should be made to feel the beauty of music form, rhythm and melody and find the beauty of music through music appreciation, singing, performance and practice under the teaching of accurate voice concept. Moreover, teachers should guide the students to directly feel the capacity of music by holding basic emotion characteristics and framework of vocal music works. In the development process of teaching activities, therefore, whether the students have aesthetic voice is served as the basis for vocal music education. The basic condition and basis for vocal music art aesthetics is the aesthetics of singing. The artistic charm of human voice has been always exaggerated and discussed by European philosophy of classical vocal music or Chinese philosophy of traditional vocal music. The vocal music art surpasses the charm of any musical instrument. The only reason is that human voice is of abundant aesthetics.

In the process of vocal music teaching, the training for voice skills contains the internal significance of aesthetics. With Bel Canto as an example, it was sourced from Italy. It is publicized around the world. No matter in whichever way it is translated, it is correlated with the word "America". "Legato" is translated as "coherent", which is the first element of aesthetics of Bel Canto. We should enhance the coherent and identical beauty of voice as well as the span concept of time and space of aesthetic characteristic. In essence, Chinese national music and European classical music are performed according to the basic standards for vocal music aesthetics. Then, it is the "resonance", namely the beauty generated by resonance of human voice. At the same time, this aesthetic standard is acknowledged as the basic standard for resonance of human voice. This aesthetic standard emphasizes more the beauty, tridimensional character and universality of human voice as well as looseness, roundness and smoothness of voice. In ordinary vocal music teaching, the following specific techniques can be used:

(1) Vocal music teachers should make specific teaching plans according to actual teaching conditions and take the students as subjects of teaching. However, teachers can not put themselves in the first place. Moreover, vocal music teachers should 
also make adjustment to the current teaching modes according to continuous changes and development. Only in this way, the students can be made to mould accurate and perfect aesthetics of vocal music in a short period. (2) At present, much progress has been made to the multimedia teaching technology for vocal music teaching. Therefore, it is relatively reasonable for us to properly utilize the multimedia technology in the process of vocal music teaching. Therefore, the students should be allowed to use digital camera to record their singing, when they failed to make standard and real-time analysis on the teaching, so as to let them learn about how to listen to and try to figure out their voice. Then, teachers should give effective guidance. After a long period in this way, students can have a clear concept of singing, resulting in effective establish the concept of vocal music aesthetics. (3) All students differ from others in terms of teaching observation. Through mutual observation and stimulation, students should be guided to how to make independent reflections. For instance, students can be made to listen to each other while listening to their teachers; or they can mutually speculate and appreciate in the process of teaching report. Through these teaching speculations, the students can analyze mutual advantages and find disadvantages of themselves and others. Under the guidance of teachers, the students can set up their aesthetics of vocal music teaching in a faster way.

\section{Conclusion}

To sum up, the major significance of vocal music aesthetics was always neglected by us in the daily teaching activities of vocal music. Due to strict requirements of vocal music art for practice and aesthetics, the aesthetic character runs through the whole process of music activities. In the process of vocal music teaching, much important attached to musical technology violates the essence of music art teaching. As far as I know, many teachers laid the emphasis on voice training in professional classes. For courses in the postgraduate period, technical training and improvement was also made. Moreover, the theoretical course of vocal music aesthetics was not offered for students in any grade. Teaching for students in different stages was basically the same. Thus, it can be seen that the advocacy and development of aesthetic consciousness is of great importance in the process of vocal music teaching.

\section{References:}

[1] Guo Jianmin, Vocal Music Culturology [M], Shanghai: Shanghai Music 
Publishing House, 2007, 8;

[2] Dai Dingcheng, Outlook on Music Education [M], Shanghai: East China Normal University Press, 2001, 12;

[3] Yu Dugang, Vocal Music Art Aesthetics [M], Beijing: People’s Music Publishing House, 2008, 2;

[4] Wang Aihong, Aesthetic Nature of Singing Thought in Vocal Music Teaching [J], Beauty \& Times, 2010, (09). 